\title{
A Tri-band Planar Inverted-F Antenna with Complementary Split Ring Resonator and Reactive Impedance Surface for Wireless Application
}

\author{
Tejaswi Jadhav \\ Electronics Engineering Department \\ Walchand College of Engineering \\ Sangli, Maharashtra, India \\ tejaswi.jadhav@walchandsangli.ac.in
}

\author{
Shraddha Deshpande \\ Electronics Engineering Department \\ Walchand College of Engineering \\ Sangli, Maharashtra, India. \\ Shraddha.deshpande@walchandsangli.ac.in
}

\begin{abstract}
In this paper, a compact, tri-band Planar Inverted-F Antenna (PIFA) using Complementary Split Ring Resonator (CSRR) and Reactive Impedance Surface (RIS) is presented for multiband application. The structure of the PIFA consists of a metallic CSRR and $5 \times 6$ periodic unit RIS cells, which accomplishes miniaturization and improves bandwidth and multiband. The RIS metamaterial plane lies between two substrates and acts as a loading function, reducing the volume of the antenna. The measured and simulated results are consistent for a manufactured prototype. The overall size of the antenna is $22.71 \times 3.451 \times 2.59 \mathrm{~mm}$. The PIFA shows a tri-band with an $\mathrm{S} 11<$ $-10 \mathrm{~dB}$ bandwidth of approximately $17.08 \%(2.26-2.67 \mathrm{GHz})$, $5.14 \%(6.85-7.21 \mathrm{GHz})$ and $19.44 \%(7.44-9.19 \mathrm{GHz})$ under measurement. The antenna radiates a wave in a preset direction with realized gains ranging from 3.21 to $8.1 \mathrm{dbi}$. The CSRR and RIS improve the performance of the antenna for WLAN, C-band, and $\mathrm{X}$-band applications.
\end{abstract}

Keywords-complementary split ring resonator; gain; multiband; planar inverted-F antenna; reactive impedance surface; wideband

\section{INTRODUCTION}

With the rapid advancement of wireless applications, lightweight, low-cost, and often omnidirectional radiation pattern antennas are becoming increasingly popular. With its low profile and ease of implementation, the Planar Inverted-F Antenna (PIFA) is a good radiator for applications such as handheld communication, Global Positioning System (GPS), microwave sensors, Wireless Local Area Networks (WLANs), Synthetic Aperture Radar (SAR), etc.. The PIFA has been used in wireless networking applications, such as WLAN, RadioFrequency Recognition (RFID), and satellite navigation systems because of its low profile and light weight. Broadside coupled Split-Ring Resonator (SRR) inclusions in the magnetic superstrate were studied in [1] and a lower resonance frequency was utilized using a metamaterial-based dual-band in [2], an asymmetrical meander lines SRR [3], and a cross-coupled interlinked SRR based metamaterial [4]. The combination of the thickness and feed position substantially increases the bandwidth of the desired frequencies discussed in [5] and a cross-shaped slot with a T-shaped patch is used for wideband in [6]. A dual-band operation is addressed by additionally loading an electrically small CSRR structure in [7]. A metamaterialbased RIS has been used in the slot-loaded patch for antenna optimization in [8]. A tri-band antenna was presented in [9] and a CSRR loaded multiple-input-multiple-output antenna with electrically small elements and reduced mutual coupling in [10]. A Fractal PIFA and SRR printed on a conductor-backed dielectric substrate were used to create an artificial magnetic conductor in $[11,12]$. A four-port diversity-based multiband antenna with high element isolation was presented in [13]. A CSRR has been used for miniaturization including the ground plane in [14]. A rectangular CSRR for the PIFA using a branch line and quad-band elements was arranged properly to implement a four-element MIMO configuration in $[15,16]$. Improved narrow bandwidth and size reduction of an antenna were discussed in $[17,18]$. Three resonant modes using an F-Tshaped radiating structure by a trapezoidal feeding plate were presented in $[19,20]$. The portable wireless device system referred to in [21] is small in size and multi-band. The antenna structure is built around capacitive slots, which allow the multiband behavior described in [22]. A loop antenna loaded with a Coplanar Strip (CPS) line was added along with two switches that allow the antenna perimeter to be varied to cover 7 different bands [23]. The CPS line is combined with two switches to vary the antenna perimeter to cover 7 different bands, and an Artificial Magnetic Conductor (AMC) was used as the reflector plane in [24]. The PIFA is a built-in mobile antenna that compensates for polarization issues, narrow bandwidth, lower gain, and operates multiple frequency bands.

In this paper, the CSRR and the RIS metamaterial are used to reduce the antenna size while improving the impedance bandwidth and multiband application. The drawbacks of the PIFA are reduced with an optimization technique, and a new, advanced, low-profile, and effective design of a PIFA with CSRR and RIS for multiband operations is implemented.

\section{THE PIFA}

\section{A. Conventional Antenna}

The proposed tri-band PIFA using CSRR and RIS is shown in Figure 1. The overall dimensions of the antenna are $22.71 \times 3.456 \times 2.59 \mathrm{~mm}$, which allows its use in portable 
systems. The standard PIFA consists of only a metallic patch element positioned above a ground surface, a dielectric constant, a microstrip line feeding mechanism on the ground surface, and a short-circuiting pin. The basic characteristic of the antenna, is the form of the letter F in English, thus it is called the inverted-F antenna. The PIFA is attached to the antenna ground plane. The PIFA ground plane scale on the PCB board has average dimensions of $56.4 \mathrm{~mm} \times 33.5 \mathrm{~mm}$ with a $1.59 \mathrm{~mm}$ antenna height of FR4 dielectric substrate $(\varepsilon \mathrm{r}=4.4$, $\tan \delta=0.02$ ). The overall dimensions of the antenna substrate are $70 \times 50 \mathrm{~mm}$.

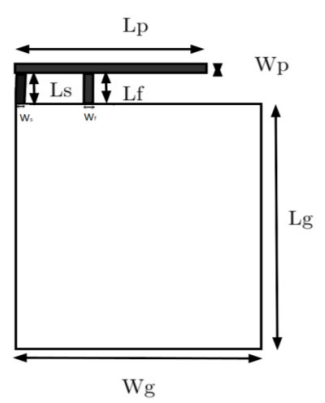

(a)

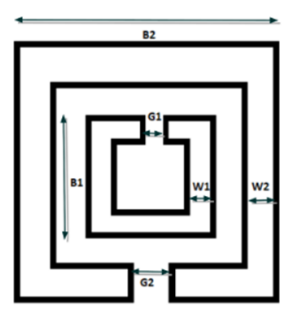

(c)

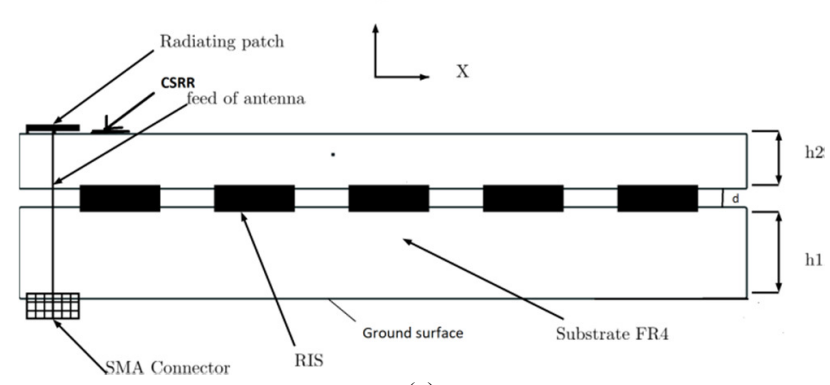

(e)

Fig. 1. The proposed PIFA with CSRR and RIS.

The PIFA is made up of a metallic module that is mounted on the bottom side of the substrate. RIS is a periodic structure designed, which can significantly improve the bandwidth and radiation characteristics. As shown in Figure 1(b), The RIS substrate is made up of two-dimensional periodic metallic patches printed on a metal-backed high dielectric substance. The CSRR is etched on the metal-plane resonator. Figure 1(c) shows a schematic view of the rectangular CSRR.

\section{B. PIFA with CSRR AND RIS}

The metallic square unit structure is mounted on the top side of the dielectric material in the PIFA configuration (FR4).
TABLE I. GEOMETRIC DIMENSIONS OF THE PROPOSED PIFAWITH CSRR AND RIS

\begin{tabular}{|c|c|c|c|}
\hline Parameters & Value (mm) & Parameter & Value (mm) \\
\hline $\mathrm{Lp}$ & 22.71 & $\mathrm{Wp}$ & 3.45 \\
\hline $\mathrm{Lg}$ & 56.4 & $\mathrm{Wg}$ & 41.68 \\
\hline $\mathrm{Ls}$ & 4.6 & $\mathrm{Ws}$ & 2.1 \\
\hline $\mathrm{Lf}$ & 4.6 & $\mathrm{Wf}$ & 2.1 \\
\hline $\mathrm{B} 1$ & 5.5 & $\mathrm{~W} 1$ & 1 \\
\hline $\mathrm{B} 2$ & 9 & $\mathrm{~W} 2$ & 1 \\
\hline $\mathrm{G} 1$ & 1.5 & $\mathrm{G} 2$ & 1.5 \\
\hline $\mathrm{a} 1$ & 0.8 & $\mathrm{~g} 1$ & 0.34 \\
\hline $\mathrm{a} 2$ & 0.9 & $\mathrm{~g} 2$ & 0.28 \\
\hline $\mathrm{h} 1$ & 1.59 & $\mathrm{~h} 2$ & 1 \\
\hline
\end{tabular}

The design of the RIS contains $5 \times 6$ periodic unit cells. The RIS uses episodic metallic square unit cells that are joined and organized one after another on a dielectric substrate. The surface of RIS is perpendicular to the plane. The lateral dimensions of the PIFA are almost the same size as the ground element for the PIFA configuration. Using the exact picture formulation will reduce the interaction between its image and the elemental source in the RIS. The RIS can enhance impedance bandwidth and reduce the size of the PIFA antenna. It is between perfectly electric and magnetic conductor (PEC and PMC) surfaces. For better impedance matching, the PIFA has a single side-feed spot.

The CSRR is a mirror image of an SRR in a metasurface resonator. It consists of two concentric metallic rectangles, each with a slit in the middle. A rectangular CSRR structure is engraved on the dielectric substrate of the proposed antenna, as shown in Figure 1(d). The widths of the rectangular inner and outer CSRR are W1 and W2 and the distances between the rectangular gap are G1 and G2. Therefore the gap between the rectangular CSRR is $1-1.5 \mathrm{~mm}$. The width of the metallic slot is between 0.9 and $1 \mathrm{~mm}$. The proposed PIFA with CSRR and RIS design parameter dimensions is described in Table I. A fixed metallic inverted-F patch on the top is adjacent to the substrate (h2) and a ground plane of the antenna is on the bottom side of the antenna substrate (h1). The rectangular patch is fed by an electromagnetically coupled microstrip feed line that is sandwiched between two FR4 dielectric substrates, each with a thickness $\mathrm{h} 1$ of $1.59 \mathrm{~mm}$ and an $\mathrm{h} 2 \mathrm{of} 1 \mathrm{~mm}$. Figure $1(\mathrm{e})$ shows the front view (cross-section) of the modified PIFA with CSRR and RIS. The metamaterial unit cell has extracted relative negative permittivity at its resonance frequency.

\section{DESIGN OF THE PROPOSED PIFA}

\section{A. Proposed Antenna Equation}

The design of the PIFA is using the transmission line model, which has 3 essential parameters, resonance frequency $\left(f_{0}\right)$, selection of a dielectric substrate $(\varepsilon r)$, and substrate height (h). The geometric radiating patch length $(L p)$, patch width $(W p)$, ground length $(L g)$, and ground width $(W g)$ have been calculated by using the mathematical model in [21]. The patch width $(W p)$ of the PIFA is:

$$
W p=\frac{c}{2 f_{0} \sqrt{\frac{\varepsilon e f f+1}{2}}}
$$

The patch length $(L p)$ of the PIFA is calculated by:

$$
L=\frac{\lambda_{g}}{4}
$$




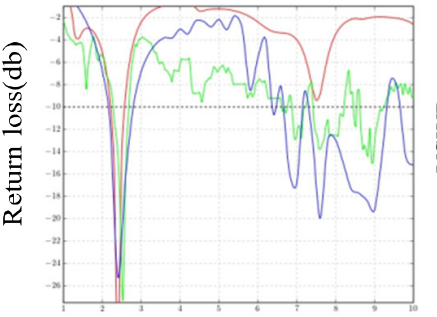

Frequency

(a)

PIFA Antenna

PIFA with CSRR and RIS

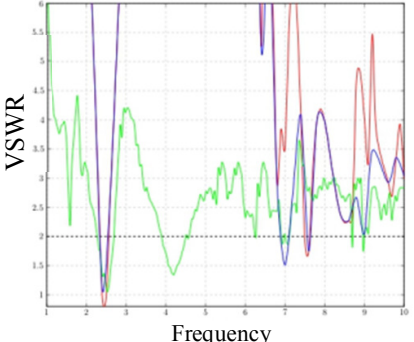

equency

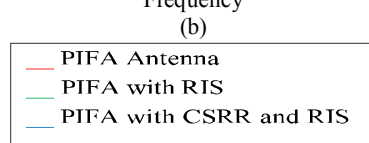

Fig. 2. (a) Simulated return loss of PIFA with and without CRSS and RIS (b) Simulated VSWR of PIFA with and without CRSS and RIS.

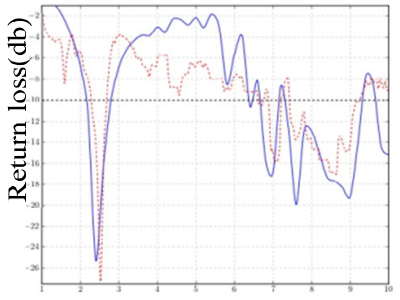

Frequency $(\mathrm{GHz})$

(a)

Simulated Return Loss

Measured Return Loss

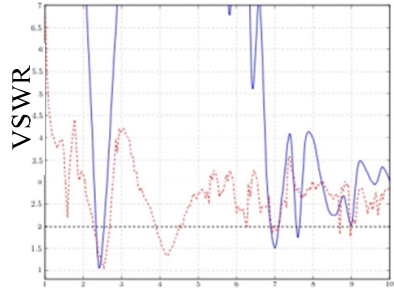

Frequency $(\mathrm{GHz})$ (b)
Simulated VSWR

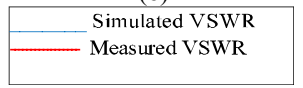

Fig. 3. (a) Measured and simulated Return Loss of PIFA with CSRR and RIS. (b) Measured and simulated VSWR of PIFA with CSRR and RIS.

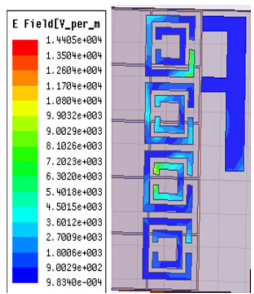

(a)

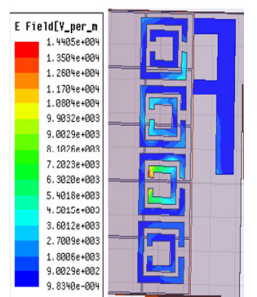

(b)

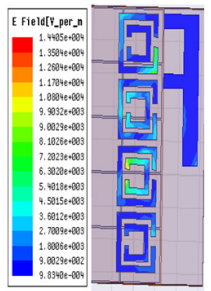

(c)

Fig. 4. Surface current distribution of the proposed PIFA at (a) $2.4 \mathrm{GHz}$, (b) $7 \mathrm{GHz}$, (c) $9 \mathrm{GHz}$

\section{B. Parametric Study}

The PIFA with and without CSRR and RIS has undergone parametric analysis and the results of the simulation are presented in Figure 2. The study was carried out by placing metamaterial surfaces on an antenna dielectric substrate while keeping all other measurements stable. Figures 3(a) and 3(b) display the simulation return loss and VSWR of the PIFA, which is tuned to resonate at $2.45 \mathrm{GHz}, 7 \mathrm{GHz}$, and $9 \mathrm{GHz}$ with the CSRR's dimensions modified. All geometric dimensions of the inside and the outside rectangle of the CSRR are listed in Table I. As a result, the slit width was held at $1.5 \mathrm{~mm}$. The resonant frequency of the antenna decreased as the length of the rectangular CSRR increased. The antenna resonant frequency increased, multiband was generated by increasing the width of the CSRR and the distance between the two squares. The antenna was tuned for multiband by adjusting these parameters. The patch's presence on the top of the CSRR

produced a lower than the actual patch's resonant frequency. This behavior is observed for different CSRR parameters in the proposed study and is consistent with previous findings.

\section{EXPERIMENTAL RESULTS AND DISSCUSSION}

\section{A. Return Loss}

The PIFA shows a tri-band with an S11<-10dB bandwidth of approximately $27.25 \%(2.1467-2.80 \mathrm{GHz}), 5.71 \%(6.70-$ $7.10 \mathrm{GHz})$, and $22.46 \%(7.30-9.3214 \mathrm{GHz})$ under simulated and $17.08 \%(2.26-2.67 \mathrm{GHz}), 5.14 \%(6.85-7.21 \mathrm{GHz})$ and $19.44 \%$ (7.44-9.19GHz) under measurement respectively. Bandwidth, polarization, gain, VSWR, and return loss of the PIFA antenna were measured in a Vector Network Analyzer (VNA). The simulated and fabricated results obtained from the output parameters are presented in Figure 3(a)-(b). The developed antenna is demonstrating high impedance matching in mobile application. Table II represented the comparison of the PIFA with previous works in terms of geometric measurements, miniaturization, frequency spectrum, gain, and bandwidth.

\section{B. Voltage Standing Wave Ratio}

The Voltage Standing Wave Ratio (VSWR) of the PIFA is shown in Figure 3(b). The VSWR values at $2.4 \mathrm{GHz}, 7 \mathrm{GHz}$, and $9 \mathrm{GHz}$ are almost $1.32,1.92$, and 2.07 respectively, which is very effective in the fabrication process. VSWR should lie in the range of 1 to 2 , indicating best antenna performance. It has used the input power of an antenna transmitted to the patch, as well as better impedance matching.

\section{Current Distribution}

The current distribution of PIFA with CSRR and RIS is determined through HFSS simulations. Figure 4 indicates the surface current distribution of the PIFA to determine the current with the RIS and the ground surface. The ground surface disrupts the current distribution of PIFA, causing CSRR. As a result, the propagation of electromagnetic waves was controlled by the substrate layer, port excitation, and changes in resonant response. The current distribution of $2.4 \mathrm{GHz}, 7 \mathrm{GHz}$, and $9 \mathrm{GHz}$ is shown in Figure 4.

\section{Gain}

For a handheld unit, the gain of the PIFA, as shown in Figure 5 is acceptable for a good multiband antenna. For operating bands $2.4,7$, and $9 \mathrm{GHz}$, the PIFA gain is $8.1,3.13$, and $7.26 \mathrm{dbi}$, respectively. The average gain of an antenna across its operating bandwidth for a quad-band is $6.16 \mathrm{dbi}$.

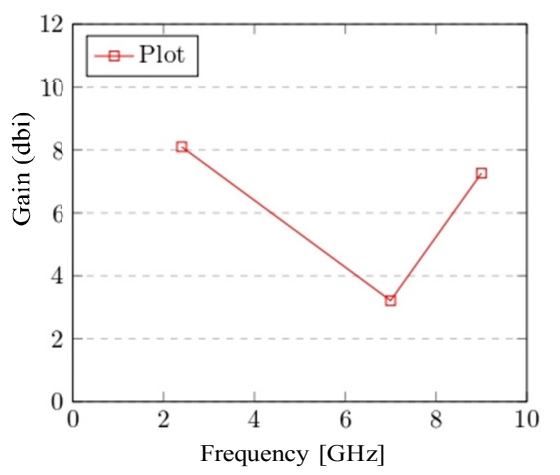

Fig. 5. Measured gain of the PIFA with CSRR and RIS. 
TABLE II. COMPARISON WITH PREVIOUS WORKS

\begin{tabular}{|c|c|c|c|c|}
\hline Ref. & Size & $\begin{array}{c}\text { No of } \\
\text { bands }\end{array}$ & $\begin{array}{c}\text { Operating } \\
\text { frequency (GHz) }\end{array}$ & Gain (dBi)) \\
\hline$[5]$ & $25.6 \times 26 \times 3.57$ & 3 & $2.09 / 3.74 / 5$ & $2.05 / 2.32 / 3.47$ \\
\hline$[8]$ & $34 \times 17 \times 8$ & 3 & $0.94 / 1.79 / 2.46$ & $0.4 / 1.7 / 1.1$ \\
\hline$[11]$ & $16.5 \times 11.5 \times 5$ & 3 & $2.4 / 5.2 / 5.8$ & $4.44 / 4.91 / 4.94$ \\
\hline$[15]$ & $90 \times 42 \times 7.5$ & 4 & $1.15 / 2.42 / 3.6 / 5.3$ & $1.45 / 1.6 / 3.56 / 4$ \\
\hline$[16]$ & $18.35 \times 16.4 \times 4.0$ & 3 & $2.1 / 2.6 / 3.5$ & $2.73 / 3.84 / 4.8$ \\
\hline$[20]$ & $25 \times 11 \times 8$ & 3 & $2.4 / 5.2 / 5.75$ & $1.6 / 2.3 / 4.4$ \\
\hline$[21]$ & $26 \times 20 \times 1.6$ & 3 & $2.4 / 3.5 / 5.8$ & $2.24 / 2.8 / 2.6$ \\
\hline Proposed & $22.7 \times 3.45 \times 2.59$ & 3 & $2.4 / 7 / 9$ & $8.1 / 3.213 / 7.26$ \\
\hline \multicolumn{5}{r}{}
\end{tabular}

\section{Radiation Pattern}

Figure 6 indicates the E-Plane and H-plane antenna radiation patterns $\left(\mathrm{Phi}=0^{\circ}\right.$ and $\mathrm{Phi}=90^{\circ}$ ) simulated in HFSS. The electric or magnetic field of the PIFA affects the radiation pattern with CSRR and RIS.
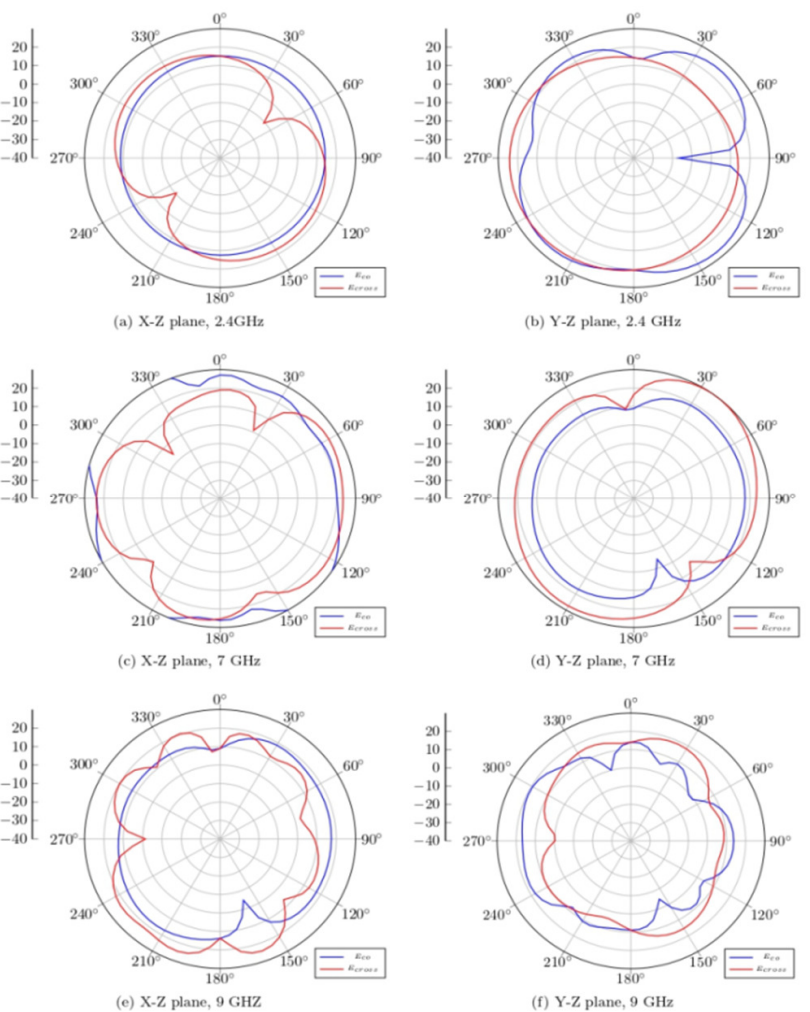

Fig. 6. Radiation pattern of the X-Z and $\mathrm{Y}-\mathrm{Z}$ planes of the proposed PIFA at $2.4,7$, and $9 \mathrm{GHz}$.

The verified PIFA radiation patterns with metasurface for wireless applications are $2.4,7$, and $9 \mathrm{GHz}$. The wave path of the maximum antenna radiates along the $\mathrm{Z}$-axis, and the wave port 1 exits the simulation. The radiation pattern of the antenna (co-plane and cross-plane) is illustrated in Figure 6 for $\varphi=0^{0}$ and $\varphi=90^{\circ}$ at $2.4,7$ and $9 \mathrm{GHz}$. The radiation pattern of the PIFA (co-plane and cross-plane) in the $\varphi=0^{\circ}$ and $\varphi=90^{\circ}$ of the XY plane. Figures 7(a)-(b) show a photograph of the manufactured CP-PIFA with CSRR and RIS.

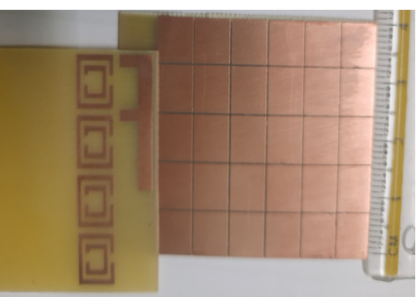

(a)

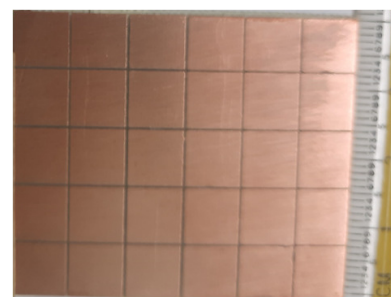

(b)
Fig. 7. Photograph of the fabricated PIFA with CSRR and RIS.

\section{CONCLUSION}

A compact, tri-band, PIFA with CSRR and RIS, suitable for WLAN, C-band, and X-band applications PIFA was presented in this paper. The PIFA has multiple bands with $\mathrm{S} 11<-10$ and bandwidth of approximately $17.08 \%, 5.14 \%$, and $19.44 \%$ measured at $2.4,7$, and $9 \mathrm{GHz}$ respectively. The antenna radiates a wave in a preset direction with realized gains ranging from 3.21 to $8.1 \mathrm{dbi}$. The parametric analysis indicates that a small change in the rectangular CSRR has a significant impact on the antenna impedance mapping. It also increases the bandwidth and provides better gain with the same dielectric substrate and radiating patch. The benefit of the multiple bands on the PIFA is shown on the radiation pattern, broadband, impedance adequacy, and gain of their operating bandwidth.

\section{REFERENCES}

1] H. Attia, M. Bait-Suwailam, and O. Ramahi, "Enhanced Gain Planar Inverted-F Antenna with Metamaterial Superstrate for UMTS Applications," Piers Online, vol. 6, no. 6, pp. 585-588, Jan. 2010, https://doi.org/10.2529/PIERS100422003051.

[2] T. Ramachandran, M. R. I. Faruque, and E. Ahamed, "Composite circular split ring resonator (CSRR)-based left-handed metamaterial for C- and Ku-band application," Results in Physics, vol. 14, Sep. 2019, Art. no. 102435, https://doi.org/10.1016/j.rinp.2019.102435.

[3] M. Alibakhshi-Kenari, M. Naser-Moghadasi, and R. a. Sadeghzadeh, "Bandwidth and radiation specifications enhancement of monopole antennas loaded with split ring resonators," IET Microwaves, Antennas \& Propagation, vol. 9, no. 14, pp. 1487-1496, 2015, https://doi.org/ 10.1049/iet-map.2015.0172.

[4] Md. Moniruzzaman, M. T. Islam, Md. Tarikul Islam, M. E. H. Chowdhury, H. Rmili, and Md. Samsuzzaman, "Cross coupled interlinked split ring resonator based epsilon negative metamaterial with high effective medium ratio for multiband satellite and radar communications," Results in Physics, vol. 18, Sep. 2020, Art. no. 103296, https://doi.org/10.1016/j.rinp.2020.103296.

[5] H. F. AbuTarboush, R. Nilavalan, T. Peter, and S. W. Cheung, "Multiband Inverted-F Antenna With Independent Bands for Small and Slim Cellular Mobile Handsets," IEEE Transactions on Antennas and Propagation, vol. 59, no. 7, pp. 2636-2645, Jul. 2011, https://doi.org/ 10.1109/TAP.2011.2152350

[6] X. Jing, Z. Du, and K. Gong, "Bandwidth enhancement design of PIFA with slotted T-shaped ground plane," Microwave and Optical Technology Letters, vol. 48, no. 10, pp. 2106-2108, 2006, https://doi.org/10.1002/mop.21875.

[7] H. Kang and S. Lim, "Electrically Small Dual-Band Reconfigurable Complementary Split-Ring Resonator (CSRR)-Loaded Eighth-Mode Substrate Integrated Waveguide (EMSIW) Antenna," IEEE Transactions on Antennas and Propagation, vol. 62, no. 5, pp. 2368-2373, May 2014, https://doi.org/10.1109/TAP.2014.2308532.

[8] L. Bernard, G. Chertier, and R. Sauleau, "Wideband Circularly Polarized Patch Antennas on Reactive Impedance Substrates," IEEE Antennas and Wireless Propagation Letters, vol. 10, pp. 1015-1018, 2011, https://doi.org/10.1109/LAWP.2011.2168803. 
[9] D. Qi, B. Li, and H. Liu, "Compact triple-band planar inverted-F antenna for mobile handsets," Microwave and Optical Technology Letters, vol. 41, no. 6, pp. 483-486, 2004, https://doi.org/10.1002/mop.20179.

[10] D. K. Ntaikos and T. V. Yioultsis, "Compact split-ring resonator-loaded multiple-input-multiple-output antenna with electrically small elements and reduced mutual coupling," IET Microwaves, Antennas \& Propagation, vol. 7, no. 6, pp. 421-429, 2013, https://doi.org/10.1049/ iet-map.2012.0688.

[11] S. N. Azemi, A. A. Al-Hadi, R. B. Ahmad, P. J. Soh, and and F. Malek, "Multiband Fractal Planar Inverted F Antenna (F-PIFA) for Mobile Phone Application," Progress In Electromagnetics Research B, vol. 14, pp. 127-148, 2009, https://doi.org/10.2528/PIERB09030802.

[12] A. Ramachandran, S. Mathew, V. Rajan, and V. Kesavath, "A Compact Triband Quad-Element MIMO Antenna Using SRR Ring for High Isolation," IEEE Antennas and Wireless Propagation Letters, vol. 16, pp. 1409-1412, 2017, https://doi.org/10.1109/LAWP.2016.2640305.

[13] M. S. Sharawi, M. U. Khan, A. B. Numan, and D. N. Aloi, "A CSRR Loaded MIMO Antenna System for ISM Band Operation," IEEE Transactions on Antennas and Propagation, vol. 61, no. 8, pp. 42654274, Aug. 2013, https://doi.org/10.1109/TAP.2013.2263214.

[14] S. Srivastava and T. Agrawal, "High Gain Microstrip MIMO Antenna for Wireless Applications," International Journal of Microwave and Optical Technology, vol. 12, pp. 74-81, Mar. 2017.

[15] A. Chatterjee, M. Midya, L. P. Mishra, and and M. Mitra, "Compact Dual Polarised Branch-Line Printed Inverted-F Antenna Covering Both Cellular and Non-Cellular Bands with Independent Tuning," Progress In Electromagnetics Research C, vol. 101, pp. 95-104, 2020, https://doi.org/10.2528/PIERC20030408.

[16] T. Jadhav and S. Deshpande, "Miniaturized Planar Inverted-F Antenna with Metallic Cross Branch for Mobile Communication," in 2019 International Conference on Intelligent Computing and Control Systems (ICCS), Madurai, India, May 2019, pp. 617-620, https://doi.org/ 10.1109/ICCS45141.2019.9065390.

[17] T. Jadhav and S. Deshpande, "Planar Inverted-F Antenna Using Defected Ground Surface for Mobile Application," in ICDSMLA 2019 , Singapore, 2020, pp. 611-619, https://doi.org/10.1007/978-981-151420-3_65.

[18] L. Bernard, G. Chertier, and R. Sauleau, "Wideband Circularly Polarized Patch Antennas on Reactive Impedance Substrates," IEEE Antennas and Wireless Propagation Letters, vol. 10, pp. 1015-1018, 2011, https://doi.org/10.1109/LAWP.2011.2168803.

[19] S. Zuo, Y. Yin, Z. Zhang, and W. Wu, "A compact tri-band PIFA antenna for WLAN and WiMAX applications," Microwave and Optical Technology Letters, vol. 52, no. 4, pp. 919-922, 2010, https://doi.org/ $10.1002 / \mathrm{mop} .25052$.

[20] J.-S. Sun, H.-S. Fang, P.-Y. Lin, and C.-S. Chuang, "Triple-Band MIMO Antenna for Mobile Wireless Applications," IEEE Antennas and Wireless Propagation Letters, vol. 15, pp. 500-503, 2016, https://doi.org/10.1109/LAWP.2015.2454536.

[21] N. L. Bohannon and J. T. Bernhard, "Design Guidelines Using Characteristic Mode Theory for Improving the Bandwidth of PIFAs," IEEE Transactions on Antennas and Propagation, vol. 63, no. 2, pp. 459-465, Feb. 2015, https://doi.org/10.1109/TAP.2014.2374213.

[22] A. Bousselmi, A. Gharsallah, and T. P. Vuong, "Design and Implementation of a Tri-Band Miniaturized Planar Inverted-F Antenna with Double Resonator for GPS Application," Engineering, Technology \& Applied Science Research, vol. 9, no. 6, pp. 4980-4983, Dec. 2019 , https://doi.org/10.48084/etasr.3116.

[23] S. P. R. Shastri, R. R. Singh, and K. V. Ajetrao, "Coplanar Stripline Loaded Reconfigurable Loop Antenna for WLAN and WiMAX Applications," Engineering, Technology \& Applied Science Research, vol. 8, no. 5, pp. 3479-3483, Oct. 2018, https://doi.org/10.48084/ etasr.2314.

[24] A. Bousselmi, A. Gharsallah, and T. P. Vuong, "A Novel High-Gain Quad-Band Antenna with AMC Metasurface for Satellite Positioning Systems," Engineering, Technology \& Applied Science Research, vol. 9, no. 5, pp. 4581-4585, Oct. 2019, https://doi.org/10.48084/etasr.2933. 